\title{
Greedy Method for Boarding a Partially Occupied Airplane Using Apron Buses
}

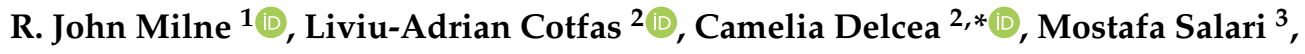 \\ Liliana Craciun ${ }^{4}$ and Anca Gabriela Molanescu ${ }^{4}$ \\ 1 David D. Reh School of Business, Clarkson University, 333 B.H. Snell Hall, Potsdam, NY 13699, USA; \\ jmilne@clarkson.edu \\ 2 Department of Economic Informatics and Cybernetics, Bucharest University of Economic Studies, \\ 010552 Bucharest, Romania; liviu.cotfas@ase.ro \\ 3 Department of Civil Engineering, Schulich School of Engineering, University of Calgary, \\ 2500 University Drive NW, Calgary, AB T2N 1N4, Canada; mostafa.salari2@ucalgary.ca \\ 4 Department of Economics and Economic Policies, Bucharest University of Economic Studies, \\ 010374 Bucharest, Romania; liliana.craciun@softscape.ro (L.C.); anca.molanescu@softscape.ro (A.G.M.) \\ * Correspondence: camelia.delcea@csie.ase.ro; Tel.: +40-769-652-813
}

Received: 16 August 2019; Accepted: 24 September 2019; Published: 1 October 2019

\begin{abstract}
This paper investigates the time to complete the boarding of a partially occupied two-door airplane when its passengers are transported from the airport terminal to the airplane using two apron buses. We propose a greedy method that assigns each passenger to a particular apron bus based on the passengers' airplane seat assignments. This greedy approach exploits the airplane's symmetry by providing essentially the same method for those boarding through the front door of the airplane as those boarding through the rear door of the airplane. The symmetrical properties of window, middle, and aisle seats of each row/side are considered in the proposed method as well. Computer simulation results indicate that, when using the greedy method, the boarding time can be reduced by up to $8.33 \%$ compared to the boarding time resulting from the best known practices in the literature, and with up to a $43.72 \%$ improvement in boarding time when compared to the boarding method commonly used in many airports. Furthermore, experimental results confirm our hypothesis that when the capacity of the apron buses exceeds the number of passengers to be transported to the airplane, the most time-efficient results of the proposed greedy method occur when an equal number of passengers are assigned to each of the two apron buses.
\end{abstract}

Keywords: airplane boarding; apron buses; agent-based modeling; two-door boarding; symmetrical boarding; greedy algorithm

\section{Introduction}

In recent years, the use of the apron buses has become a common boarding practice in airports all over the world as it offers a practical alternative to the use of the jet bridges without the need for considerable investment on behalf of the airports. Other advantages are minimizing the turnaround time as the embarkment and disembarkment can be done faster when the two doors of the airplane are used. Technical issues - such as an airplane's wingspan being too long to fit near the airport terminal or the airplane being too heavy for the tarmac at the gate-are solved through the use of the apron buses. Nevertheless, reducing the costs can also incentivize an airline company to opt for apron buses instead of jet bridges as, in some cases, the cost of having the sole use of a certain gate can be high while with the limited number of jet bridges, differential pricing policies might apply [1]. 
Being aware that airports employ apron buses for boarding purposes, some of the airline companies have adjusted their boarding ticket to include information related to which door of the airplane, front or rear door, should be selected by each passenger when arriving near the airplane [2]. This adjustment is beneficial for both the passenger as it decreases the passengers' stress by selecting the wrong door of the airplane and being forced to walk a long distance in the narrow aisle of the airplane and for the airline agencies as the boarding time decreases.

Potential cost savings, as a result of shorter turnaround time, have motivated both airline companies and researchers to reduce airplane boarding time [3-11]. As a result, a series of methods have been proposed in the literature considering one-door boarding with the use of jet bridges, while only some of them have been used in practice for airplane boarding [12]. Nyquist and McFadden [9] and Stainer and Philipp [10] report an average cost of $\$ 53.5$ per minute delay in boarding. At first glance, this cost might not seem considerably significant for a single flight, but, if accounting for the number of flights in Europe, of more than 10 million flights [13], with an average delay [14] of 14.7 minutes per flight reported by Eurocontrol in 2018, the cost becomes substantial.

In this paper, we review the newest methods in the literature for two-door boarding when apron buses are used, identify the most time-efficient methods, and propose a greedy method with the purpose of diminishing the overall boarding time in the case of the partially occupied flights. Different levels of occupancy for the airplanes are considered, ranging between $60 \%$ and $90 \%$. The greedy algorithm exploits the airplane symmetry in the front and in the rear part of the airplane and provides the same set of rules for each of the two parts. The symmetrical properties of window/middle/aisle seats of each row/side of the airplane have been considered in the proposed algorithm.

Some airline companies offer passengers the possibility to select their seat in the airplane prior to boarding, through an online check-in system (see Figure 1) or at the airport. With respect to seat selection possibility by passengers, this paper considers two situations for seat selection: random seat assignments and preferential seat assignments.

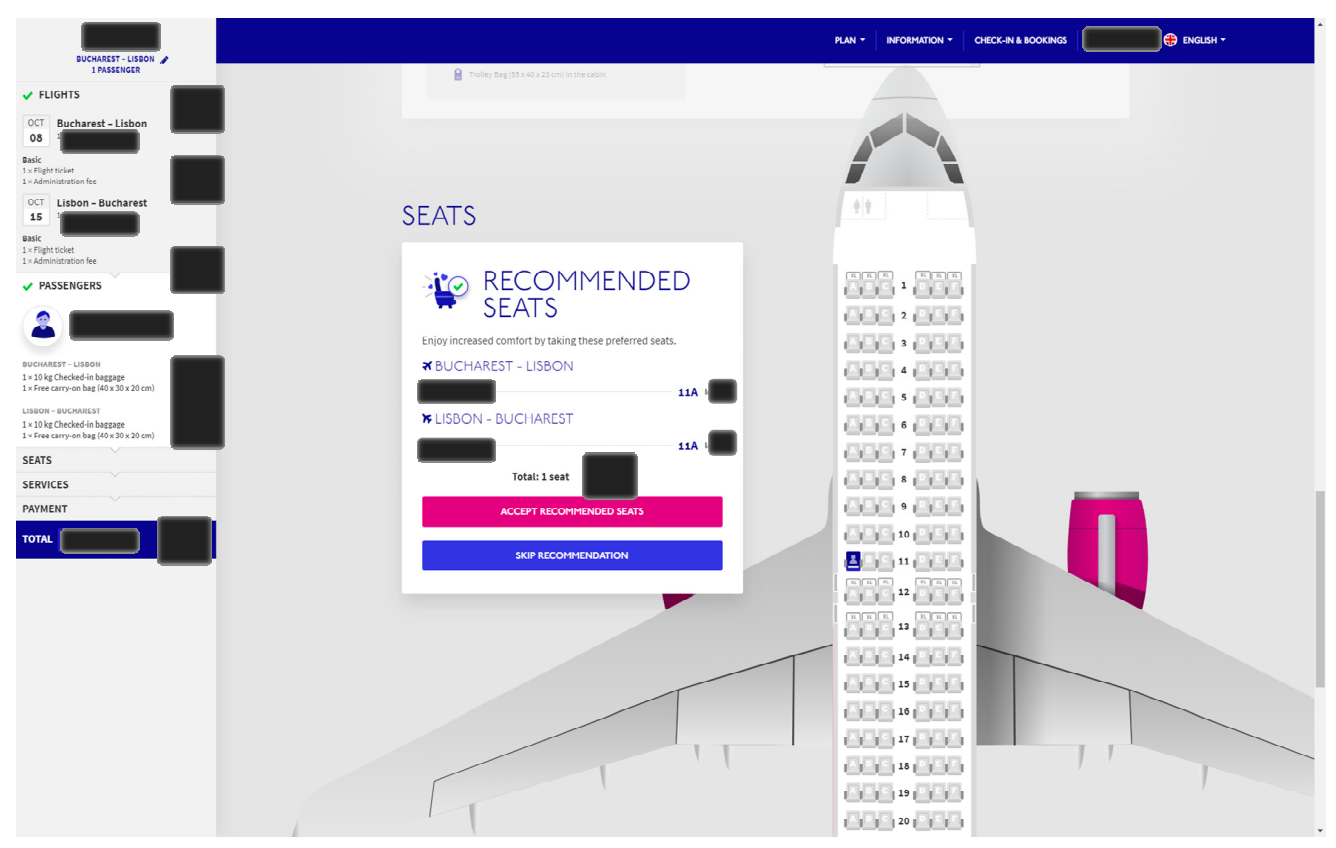

Figure 1. Seat selection through an on-line check-in platform.

With random seat assignments, the passengers' seats are randomly selected by a computer, without considering any particular scheme, while with preferential seat assignments, each passenger can select his/her seat either using the airline company webpage or at the check-in desks of the airport. To model preferential seat selection situations, we use the data extracted through a questionnaire in [12] which 
considered the passenger's preference for a window/middle/aisle seats along with the inclination to the front/middle/rear rows of the airplane and the preference/antagonism for the crowded rows.

We provide the rules associated with the greedy method and programmed the model in NetLogo [15] by taking advantages of the agent-based modeling properties. Through the use of the BehaviorSpace tool [15], the model is simulated and compared in terms of average boarding times with the best-performing methods in the literature, namely Reverse Pyramid-A, Hybrid-A, and Hybrid-B [16]. An Airbus A320 configuration is used, having 30 rows, a single economy class and two boarding doors located in the front and in the rear side of the airplane as presented in Figure 2. Considering the symmetry of the layout, we assume that all passengers with seats in rows 1-15 of the airplane will board through the airplane's front door and that the remaining passengers (those with seats in rows 16-30) will board from the rear door. Several luggage situations are also considered. For further analysis of the proposed approach, we discuss the seat and aisle interferences resulting from the methods.

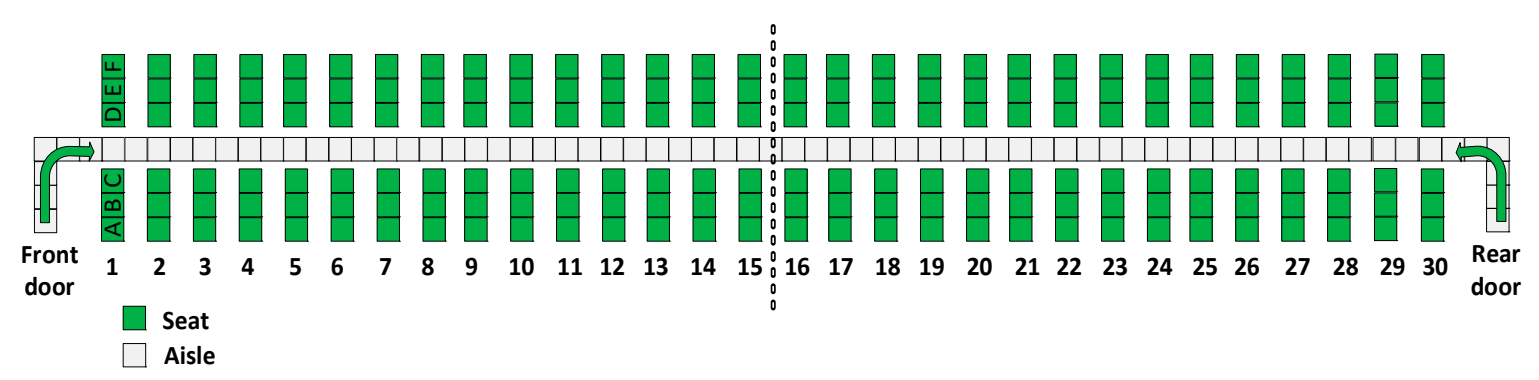

Figure 2. Airbus A320 configuration with 30 seat rows.

The remainder of the paper is organized as follows: Section 2 presents a brief literature review of the methods used in the case of jet bridges and in the case of boarding with apron buses. Section 3 discuss various aspects related to passenger movement, luggage assumptions, and seat selection. The agent-based model in NetLogo is also presented in this section along with its main features. Section 4 presents the rules of the proposed greedy method, while Section 5 presents the numerical simulation results of the proposed algorithm and compares them with the best-performing methods in the literature. In this section, we also discuss the occurrence of the seat and aisle interferences and their impact on the overall boarding time. The paper concludes with a brief summary of highlights.

\section{Literature Review}

The literature dedicated to the airplane boarding methods can be divided into two major categories with respect to the methods of transporting passengers between the terminal and the airplane: Studies that discuss/propose methods of passengers boarding when the airplane is directly connected to the airport terminal through one or two jet bridges and papers that offer methods for passengers boarding with two apron buses. A short literature review on some of the relevant papers is presented in the following section.

\subsection{Summary of the Boarding Methods for Jet Bridges Case}

When an airplane is connected to the airport terminal through one or two jet-bridges, a series of boarding methods can be used due to the direct connection between the airplane and the airport terminal. These methods are featured as boarding seat-by-seat (known as "by seat" strategies), boarding by forming groups depending on the imposed rules (the so-called "by group" strategies) or random boarding, where the passengers enter the airplane on a first-come, first-serve basis.

Among the "by group" methods, some of the well-known ones are below $[5,9,12,17,18]$ :

WilMA, in which the passengers are divided into three groups depending on the position of their seat: near the window, in the middle, or near the aisle. When the boarding process starts, the window 
seat passengers are called to board, followed by the middle seat and aisle seat passengers, respectively. Within each of the three boarding groups, passengers board in a random sequence. The method benefits from the simplicity of creating the three boarding groups and provides better boarding times than the classical random boarding method. Currently, the method is used in practice by United Airlines.

- Back-to-front: In this case, the airplane is divided into a number of rows, for group boarding, starting from the rear of the airplane, made of about $1 / 5$ of the rows at a time. The passengers having seats in each of the groups are called "by group" to board starting from those seated closest to the rear of the airplane. This method is highly employed in practice by airline companies such as Air Canada, Air China, Alaska, American Airlines, Delta, British Airways, Cathay Pacific, Eva Air, Frontier, Japan Airlines, Korean Air, Spirit and Virgin Atlantic;

- Reverse pyramid uses a diagonal scheme for boarding the groups of passengers, starting with the window seat passengers in the rear rows of the airplane and ending with those having aisle seats near the front of the airplane.

Compared to the "by group" methods, the "by seat" methods require more logistics in the airport as, in this case, each passenger is called (or otherwise aligned) individually for boarding. Some of the well-known "by seat" methods are proposed by Steffen $[4,19,20]$. In practice, the "by seat" methods are used in an adapted manner in which the airlines combine these methods' advantages with some of the advantages offered by the "by group" methods. For example, JetBlue uses a "by seat" modified reverse pyramid on the half zone for passengers boarding, while KLM, on selected flights, has used a method that combines WilMA and Back-to-front in a "by seat" manner [12]. Additional methods, "by seat" or "by group", and their boarding rules can be found in [4,8,21-25].

As for the random boarding methods, both open seating methods (in which passengers do not have assigned seats) and random boarding with assigned seats methods are used in practice by airline companies such as Southwest, Air France, EasyJet, Lufthansa, Ryanair, Tarom, WizzAir, etc. [12].

The literature examines various factors related to airplane boarding methods. These factors include: passenger movement [4,19], the presence of carry-on hand luggage $[3,4,6,7,26]$, seat selection [19,27], airplane characteristics, e.g., the number of rows or airplane type [3,5,20,27,28], airplane occupancy [3,8,20,23,24,26,29], costs [9], the existence of pre-boarding areas [10], seat and aisle interferences [30-32], the presence of two jet bridges for boarding [9,33-36], etc. A study made by Boeing [37], and summarized in [36], states that the time reduction when two doors are used for boarding instead of just one door is almost five minutes on a 17 minute boarding time, while Nyquist and McFadden [9] conclude that, in some cases, the time reduction when moving from boarding using just one door to two doors case can be up to $61 \%$ in the no-luggage case and $33 \%$ in the case in which the passengers bring hand luggage inside the airplane.

\subsection{Summary of Boarding Methods for Apron Buses Case}

The literature related to the use of apron buses is limited. In [38], the authors propose a Back-to-front approach which reduces the boarding time by up to $8.9 \%$ when compared to the random boarding method commonly used in practice.

Thirteen boarding methods for boarding with two apron buses are proposed in [2]. These methods have been tested with a full-occupied airplane and increase a decrease in the boarding time by $5.6 \%$ to $36.6 \%$. Among them, three methods namely Reverse Pyramid-A, Hybrid-A, and Hybrid-B, provide the largest boarding time reductions, ranging between $24.2 \%$ and $36.6 \%$, depending on the passengers' luggage volumes. Figures 3-5 present the general scheme for each of these three methods. In these figures, passengers assigned to the first apron bus (i.e., first group) are designated in yellow seats while those passengers assigned to the second apron bus (i.e., second group) are designated in blue seats. Considering that Ferrari and Nagel [27] assert that the efficiency of a boarding strategy may depend on the airplane occupancy, in [16], the 13 methods have been tested on partially occupied flights, with an occupancy ranging between $60 \%$ and $90 \%$. Two cases for the seat assignments have 
been considered for the simulations: random seat assignment and random with preferences for seat assignments. The boarding time improvement recorded has been up to $38.6 \%$ in the random seat assignment case when compared to the random boarding method and up to $39.09 \%$ with preferential seat assignments. Even in this case, the three methods, Reverse Pyramid-A, Hybrid-A, and Hybrid-B, brought the highest boarding time improvement.

In this context, the present paper considers passengers boarding a two-door airplane when apron buses are used and proposes a greedy method that assigns each passenger to a particular apron bus based on the passengers' airplane seat assignments. This greedy approach exploits the airplane's symmetry by providing essentially the same method for those boarding through front door of the airplane as those boarding through the rear door of the airplane. Computer simulation results indicate that when using the greedy method, the boarding time can be reduced when compared to the random boarding and when compared to the three best-performing methods proposed in [2].

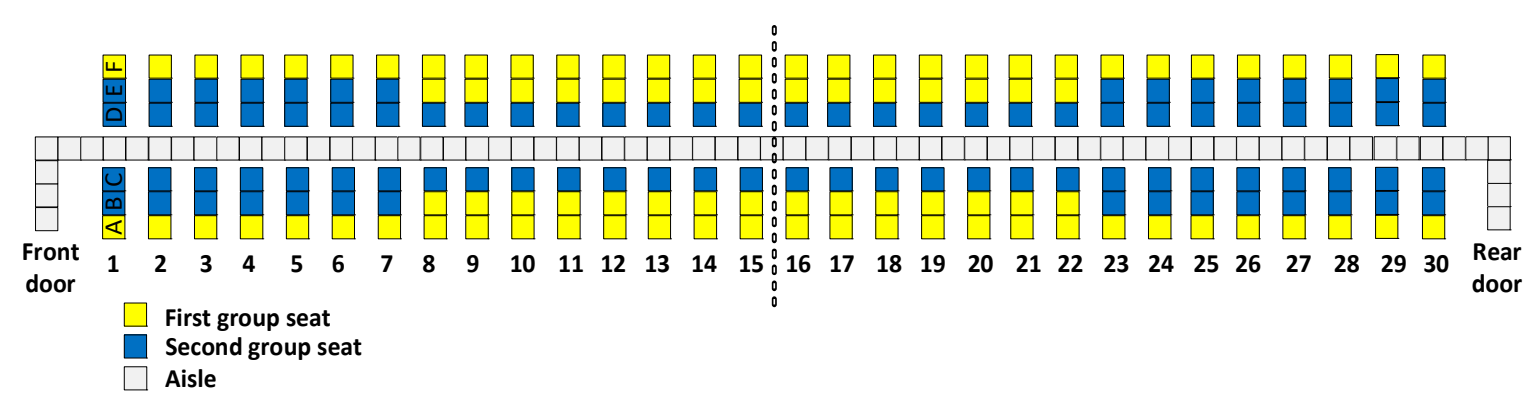

Figure 3. Reverse Pyramid-A.

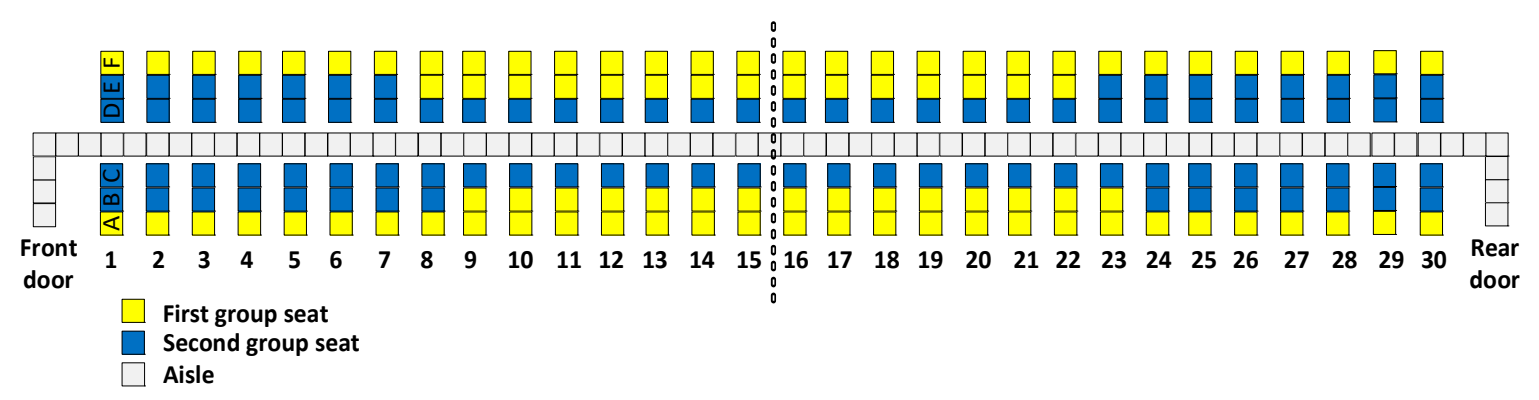

Figure 4. Hybrid-A.

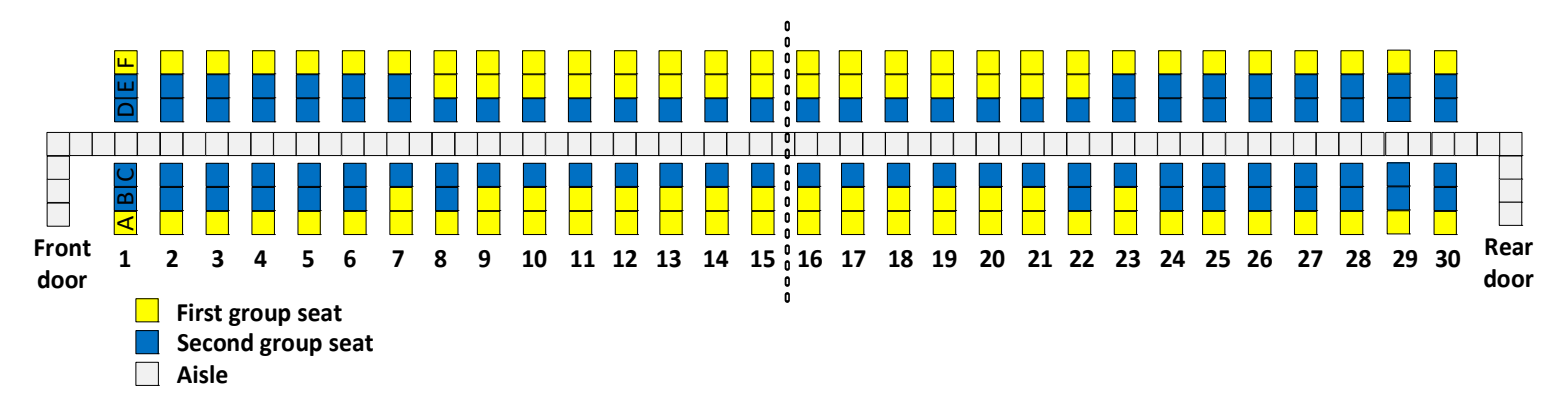

Figure 5. Hybrid-B.

\section{Passenger Seat Assignment, Movement, and Luggage Assumptions}

\subsection{Passenger Seat Assignment}

The greedy method along with the random boarding method and the three methods introduced in [2] are programmed in NetLogo (Developed at The Cenrer for Connected Learning and Computer Based Modeling Evanston, IL 60208, United States of America), which benefits from all the advantages of the agent-based modeling [39-47] and respects the main properties of the agents as they are presented 
in the literature related to autonomy, social ability, responsiveness, proactiveness, adaptability, mobility, veracity, and rationality [15,48-50]. To make the agent a realistic representative of the passengers boarding an airplane, a series of assumptions are made and several cases are considered.

The agent-based modeling GUI (graphical user interface) is presented in the Appendix A in Figure A1. It offers the possibility for the user to easily select the type of airplane under consideration, the plane capacity, the number of passengers, the luggage combination, the capacity of each of the two apron buses, etc.

In addition to selecting particular values by the use of the sliders, the agent-based model allows an individual defining of each of these characteristics, being easy to use in any modeling situation related to airplane boarding through two doors when the apron buses are used.

In the following, we discuss assumptions we made through the modeling process. For the seat assignment, we consider two types of seat assignment: random seat assignments and preferential seat assignments. With random seat assignments, we assume that all the seats occupied by the agents are randomly generated by a computer, not accounting for the passengers' preferences for particular seats or rows of the airplane. This assumption is in line with most of the existing literature on airplane passenger boarding.

On the other hand, the preferential seat assignment accounts for the preference that a passenger might have for particular seats located in the front/middle/rear rows of the airplane, or in the window/middle/aisle seats or on preference/antagonism to crowded areas. All these aspects are known for a passenger who decides to make online check-in and to select his/her seat, as, in the online platforms, one can see the airplane scheme and the already selected seats in every part of the airplane. To include these aspects in our model, we have consider the data extracted by [12] through a questionnaire and employ the same fitness function used [12] to decide the preference of each passenger towards a particular seat.

Furthermore, if one conducts his/her own study regarding a particular set of passengers' preferences towards different parts of the airplane and the importance given to this preference, the data extracted can be easily incorporated into the software code, making it even more attractive to specific researchers.

\subsection{Passenger Movement Assumptions and Luggage Assumptions}

The passenger movement assumptions are in line with $[2,16]$ as we test the proposed greedy method against the three best-performing methods of the literature for this problem in [16], Reverse Pyramid-A, Hybrid-A and Hybrid-B, by considering the same initial conditions.

Regarding the passengers' flow, we assume that all the passengers to be boarded into the airplane know which apron bus and which door of the airplane to use as they are printed on their boarding passes. Moreover, we assume passengers board their assigned apron buses and enter the airplane through their assigned door.

Once the passengers arrive at the gate and are ready to board, we assume that all the passengers having the 1st apron bus indicated on their ticket will proceed to get on that bus. When there are no more passengers yet to board the first bus, the bus transports the passengers to near the airplane. In the meantime, the 2nd bus accommodates the remaining passengers, and then proceeds to the airplane. Once arrived there, the passengers from the 1st bus select the boarding door based on the door indicated on their ticket: front or rear. Then, the passengers proceed to the door and step into the airplane in a random sequence, following a first come, first in approach. When arrived near the airplane, the passengers belonging to the 2 nd apron bus proceed in the same way the passengers of the first bus did and enter the door indicated on the boarding pass. We assume that none of the passengers in the 2nd bus will overpass the passengers already in the queue from the 1st bus. This assumption is in line with the previous observation related to the fact that we consider our passengers to be rational and behaving appropriately.

The modeling procedure using the agents tracks the passengers' movement from the time they step into the airplane until the moment they take their places in their assigned seats. The simulation 
time is measured in ticks (the time unit in NetLogo) and it is accounted from the moment the first passenger from the first bus steps into the airplane, through the front or the rear door, until the moment the final passenger from the second bus takes his/her seat.

During the boarding process when passengers walking down the aisle, we assume a default speed for the agents which can be up to $0.33 \mathrm{~m} / \mathrm{s}$. The value of the default speed is adjusted for each passengers depending on several characteristics related to the number of luggage pieces he/she is carrying on board and based on the speed of the leading passenger. We assume that no overpassing is possible while walking through the aisle (readers can find similar assumptions in [11,51,52]). When a passenger has carry-on bags, the speed is generally reduced, taking a random number between $0.2 \mathrm{~m} / \mathrm{s}$ and $0.3 \mathrm{~m} / \mathrm{s}$, which is adjusted depending on the speed of the leading passenger [2].

Minimum personal space is considered for the passengers walking down the aisle equal to $0.4 \mathrm{~m}$, this space is strictly related to the minimum comfort distance people need to feel comfortable and also to have enough space for the carry-on bag(s) [52].

Two types of passengers interferences are considered as recommended in the literature $[8,36,53,54]$ : seat and aisle interferences. The aisle interference is linked to the passengers carrying on luggage as to store it in the overhead compartment, they need a specific luggage storing time. The storing time depends on the number of hand luggage carried by a passenger as well as the already-stored luggage. Similar to Audenaert et al. [55] and [2,3,6,11,16], we allow unlimited overhead bin capacity and employ the following formula to determine luggage storage time:

$$
\begin{gathered}
\text { Tstore }=((\text { NbinLarge }+0.5 \text { NbinSmall }+ \text { NpassengerLarge } \\
+0.5 \text { NpassengerSmall }) \times(\text { NpassengerLarge } \\
+0.5 \text { NPassengerSmall }) / 2) \times \text { Trow }
\end{gathered}
$$

where:

Tstore is the time to store the luggage

NbinLarge is the number of large bags in the bin prior to the passenger's arrival

NbinSmall is the number of small bags in the bin prior to the passenger's arrival

NpassengerLarge is the number of large bags carried by the passenger

NpassengerSmall is the number of small bags carried by the passenger

Trow is the time for a passenger to walk from one row to the next (when not delayed by another passenger in front of him/her)

Observe that with Equation (1), the more large bags (NbinLarge) and the more small bags (NbinSmall) a passenger carries aboard the airplane, the longer the time (Tstore) for the passenger to store the luggage.

The values corresponding to the observed boarding time data from those other researchers have been transformed into ticks, the time unit used by NetLogo, by dividing it by 1.2 and rounding it up to the nearest integer [2]. Similar to [16], we introduce several carry-on luggage combinations (see Table 1):

Table 1. The situations considered in the simulation experiments based on the luggage carried.

\begin{tabular}{cccccc}
\hline \multirow{2}{*}{ Situation } & \multicolumn{5}{c}{ Percentages of Bags Carried by the Passengers } \\
& 0 Bags & 1 Small Bag & 2 Small Bags & 1 Large Bag & 1 Large and 1 Small Bag \\
\hline S1 & $10 \%$ & $10 \%$ & $0 \%$ & $10 \%$ & $70 \%$ \\
S2 & $15 \%$ & $20 \%$ & $5 \%$ & $10 \%$ & $50 \%$ \\
S3 & $25 \%$ & $20 \%$ & $10 \%$ & $15 \%$ & $30 \%$ \\
S4 & $35 \%$ & $25 \%$ & $10 \%$ & $15 \%$ & $15 \%$ \\
S5 & $60 \%$ & $10 \%$ & $10 \%$ & $10 \%$ & $10 \%$ \\
S6 & $80 \%$ & $5 \%$ & $5 \%$ & $5 \%$ & $5 \%$ \\
S7 & $100 \%$ & $0 \%$ & $0 \%$ & $0 \%$ & $0 \%$ \\
\hline
\end{tabular}


The S7 situation considers that none of the passengers will bring any carry-on bags on board, therefore, in this case, we expect to get zero aisle interferences.

Four types of seat interferences are considered, named Type 1, Type 2, Type 3 , and Type $4[8,36,53,54]$. As acknowledged in the literature $[8,36,53,54]$, it has been determined that there is a negative relationship between the number of seat interferences and the overall boarding time. Seat interferences (potentially) delay boarding and, thus, increase the time to complete boarding of the airplane. Figure 6 depicts the four types of seat interferences. These are all the possible types of seat interferences-covering all conditions in which a seated passenger must rise to make room for a later arriving passenger to sit down.

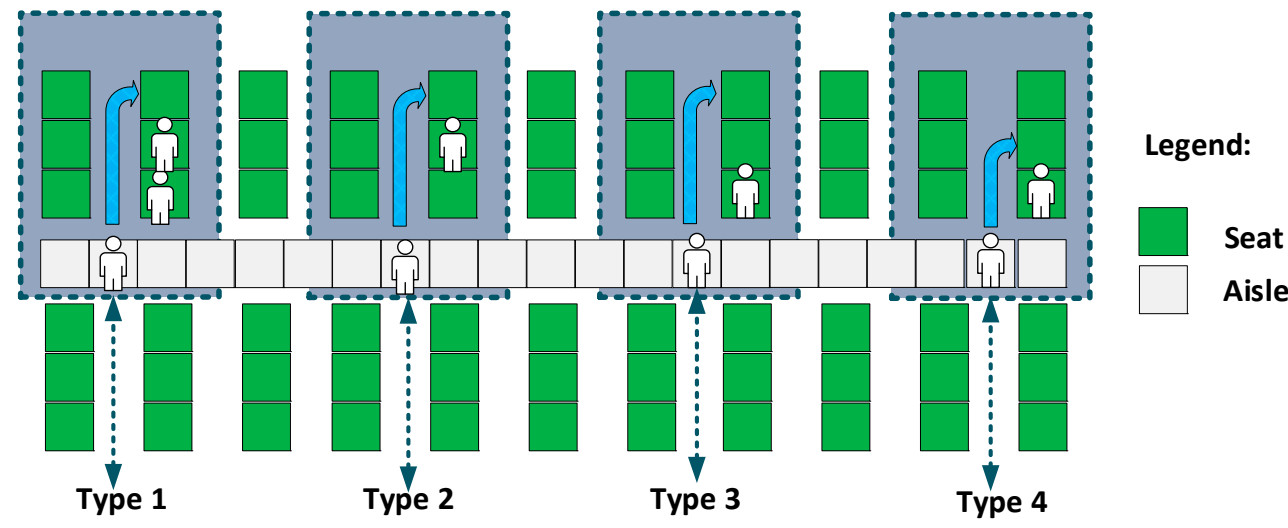

Figure 6. The types of seat interferences.

Type 1 seat interference occurs when a passenger having a seat near the window arrives in front of the row in which his/her seat is placed and observes that the middle and the aisle seats closest to his/her seat are already occupied by two other passengers. In this case, the two passengers need to leave the row - to enable the window seat passenger to take his/her seat—and after that to re-take their seats. The average duration of this process has been determined to be equal to 22 seconds, ranging between 20 and 26 seconds.

Type 2 seat interference occurs when a passenger with a middle seat occupies his/her seat, the aisle seat is free, and the passenger with the adjacent window seat arrives near the row. In this case, the passengers with middle seat exits the row—enabling the window seat passenger to sit—and then returns to his/her place. This action is considered to take, on average, 12 seconds, ranging between 10 and 13 seconds.

Type 3 and Type 4 seat interferences occur when a window or middle seat passenger arrives to his/her row after the closest aisle seat has been taken. In this case, the passenger with the aisle seat exits the row, the passenger with the window or middle seat takes his/her seat, and the aisle passenger returns to his/her place. In both cases, type 3 and type 4, this action takes 10 seconds, ranging between 9 and 13 seconds.

\section{Greedy Algorithm}

Greedy algorithms have been used in many applications (see for instance, [56]). We provide the gist of the greedy approach with a simple example. Suppose a person has a set of tasks to complete by a particular deadline. The person does not have enough time to complete all the tasks on time. Instead, the person works first on the most important task that can be completed by the deadline. After finishing that task, the person works next on the most important task that remains on the (now shorter) to-do list of tasks that can be accomplished by the deadline. The person continues selecting tasks in this way until there is not sufficient time remaining to complete any of the remaining tasks. This is called a greedy approach because for each step of the process, the person selects only a single task, based upon the importance/value of that one task-without considering the effect of that decision on later steps. 
An advantage of the greedy approach is its simplicity. It is a heuristic method, with no guarantee of optimality. Depending upon the problem, the greedy approach may or may not be effective. In the context of deciding on the passengers to board each of two apron buses with a two-door partially occupied airplane, we illustrate that the greedy approach works better than previoulsly described methods in the literature for solving this problem.

In this context, the problem is to determine which passengers-based on their seats-to assign to the first apron bus and, by default, the remaining passengers will be assigned to the second apron bus. Our proposed greedy method begins with an empty first apron bus and assigns passengers to that bus until we have assigned as many passengers as we want to assign to that first apron bus. In Section 5.1 we determine that the smallest boarding time results from having an equal number of passengers assigned to each of the two apron buses.

The most important set of passengers to assign to the first apron bus are those passengers sitting in a window seat in which its adjacent middle seat and its adjacent aisle seat are occupied. This is identified as set 1 in Table 2 indicated by the $X$ in the window (W) column and a $y$ in the middle (M) and aisle (A) columns. To ease readability, Table 2 refers only to rows in the front half of the airplane, while due the symmetry of the airplane, the same principle can be applied to rows in the back half of the airplane. For example, when Table 2 refers to rows 10-15 (in the front half of the airplane), this should be interpreted as including as well as the analogous rows 25-30 (in the rear half of the airplane).

The greedy algorithm assigns the $X$ passengers from set 1 , and then from set 2 , and so on, proceeding down the table until all the desired passengers have been assigned to the first apron bus. For the final set of passengers to be assigned to the first bus, if there is only available room on the bus for a proper subset of them, then the passengers from that subset that are seated in rows closest to the middle of the airplane will be assigned to the first bus. In general, the sets (and their implied priority) are chosen to assign passengers to the first bus in a manner that will:

- Reduce the likelihood of seat interferences (especially, interferences of type 1, secondly type 2, and third types 3 and 4); and

- Favor congestion towards the middle rows of the airplane.

For example, by assigning the window seat passengers of set 1 to the first bus, we reduce the probability of seat interferences among those window seat passengers and their adjacent middle and nearby aisle seat passengers (type 1 seat interference) and the probability of boarding after only one of those two passengers (type 2 and type 3 seat inferences). The importance of prioritizing the boarding of these passengers is emphasized by the most time-efficient methods as they allow the boarding of the window seat passengers prior to other passengers on a fully occupied airplane or partially occupied airplane. Those best performing methods, like our greedy method, also favor congestion towards the middle of the airplane for passengers assigned to the first bus and, conversely, avoid congestion near to either door of the airplane. In the context of a partially occupied airplane, a relative strength of our proposed greedy method is its differentiation of prioritized sets.

We do not prove that Table 2 contains the best possible prioritized sets of passengers to assign to the first apron bus. Instead, this table provides the best combination of prioritized sets among those we have tested. We summarize our rationale for the prioritization of these sets in the rightmost column of Table 2. More detail on the steps of the greedy algorithm may be found in Algorithm 1. 
Table 2. Prioritized sets of passenger seats to assign to the first apron bus.

\begin{tabular}{|c|c|c|c|c|c|c|c|}
\hline \multirow{3}{*}{$\begin{array}{c}\text { Set } \\
1\end{array}$} & \multicolumn{3}{|c|}{ Seats * } & \multirow{2}{*}{\multicolumn{3}{|c|}{ Rows in Front Half of the Airplane }} & \multirow{2}{*}{ Why Assign Set to Apron Bus \#1? } \\
\hline & \multirow{2}{*}{$\begin{array}{l}\mathbf{W} \\
\mathrm{X}\end{array}$} & \multirow{2}{*}{$\frac{\mathbf{M}}{\mathrm{y}}$} & \multirow{2}{*}{$\begin{array}{c}\mathbf{A} \\
\mathrm{y}\end{array}$} & & & & \\
\hline & & & & 1 & to & 15 & Avoid seat interferences type 1,2 , and 3 \\
\hline 2 & $\mathrm{X}$ & $\mathrm{y}$ & & 5 & to & 15 & Avoid seat interference type 2 in most rows \\
\hline \multirow{2}{*}{3} & $\mathrm{X}$ & & $\mathrm{y}$ & 10 & to & 15 & \multirow{2}{*}{$\begin{array}{c}\text { Avoid seat interference types } 3 \text { and } 4 \text { in } \\
\text { middle rows }\end{array}$} \\
\hline & & $\mathrm{X}$ & $\mathrm{y}$ & 10 & to & 15 & \\
\hline 4 & $x$ & $\mathrm{y}$ & & 1 & to & 4 & $\begin{array}{c}\text { Avoid seat interference type } 2 \text { in rows near } \\
\text { the door }\end{array}$ \\
\hline \multirow{2}{*}{5} & $\mathrm{X}$ & & $\mathrm{y}$ & 1 & to & 9 & \multirow{2}{*}{$\begin{array}{c}\text { Avoid seat interference types } 3 \text { and } 4 \text { in } \\
\text { most rows }\end{array}$} \\
\hline & & $\mathrm{X}$ & $\mathrm{y}$ & 1 & to & 9 & \\
\hline 6 & $\mathrm{y}$ & $\mathrm{X}$ & $\mathrm{y}$ & 13 & to & 15 & \multirow{4}{*}{$\begin{array}{l}\text { Indifferent to bus \#1 or bus \#2 except that } \\
\text { congestion is better in middle rows with } \\
\text { bus \#1. The congestion impact prioritzes } \\
\text { set } 6 \text { over set } 7 \text {. }\end{array}$} \\
\hline \multirow{3}{*}{7} & $\mathrm{X}$ & & & 13 & to & 15 & \\
\hline & & $X$ & & 13 & to & 15 & \\
\hline & & & $\mathrm{X}$ & 13 & to & 15 & \\
\hline \multirow{2}{*}{8} & $\mathrm{y}$ & & $\mathrm{X}$ & 14 & to & 15 & \multirow{2}{*}{$\begin{array}{c}\text { Causes seat interference types } 3 \text { and } 4 \text { but } \\
\text { only in middle rows }\end{array}$} \\
\hline & & $\mathrm{y}$ & $\mathrm{X}$ & 14 & to & 15 & \\
\hline 9 & $\mathrm{y}$ & $X$ & & 14 & to & 15 & $\begin{array}{c}\text { Causes seat interference type } 2 \text { but only in } \\
\text { middle rows }\end{array}$ \\
\hline \multirow[t]{2}{*}{10} & $\mathrm{y}$ & $\mathrm{y}$ & $x$ & 14 & to & 15 & \multirow{2}{*}{$\begin{array}{c}\text { middle rows } \\
\text { Potentially causes seat interferences of } \\
\text { type } 1,2 \text {, and } 3 \text { but only in the most middle } \\
\text { rows (where congestion not terrible) } \\
\text { Drawbacks of assigning set to bus \#1 }\end{array}$} \\
\hline & & & & & & & \\
\hline \multirow{4}{*}{11} & $\mathrm{y}$ & $\mathrm{X}$ & $\mathrm{y}$ & 1 & to & 12 & \multirow{4}{*}{$\begin{array}{l}\text { Indifferent to bus \#1 or bus \#2 except that } \\
\text { congestion is worse in these rows closer to } \\
\text { the door for bus \#1 assignment }\end{array}$} \\
\hline & $\mathrm{X}$ & & & 1 & to & 12 & \\
\hline & & $X$ & & 1 & to & 12 & \\
\hline & & & $\mathrm{X}$ & 1 & to & 12 & \\
\hline \multirow{2}{*}{12} & $\mathrm{y}$ & & $\mathrm{X}$ & 1 & to & 13 & \multirow{2}{*}{ Causes seat interferences type 3 and 4} \\
\hline & & $\mathrm{y}$ & $\mathrm{X}$ & 1 & to & 13 & \\
\hline 13 & $\mathrm{y}$ & $X$ & & 1 & to & 13 & Causes seat interference type 2 \\
\hline 14 & $\mathrm{y}$ & $\mathrm{y}$ & $X$ & 1 & to & 13 & $\begin{array}{l}\text { Potentially causes seat interferences of } \\
\text { type } 1,2 \text {, and } 3\end{array}$ \\
\hline
\end{tabular}

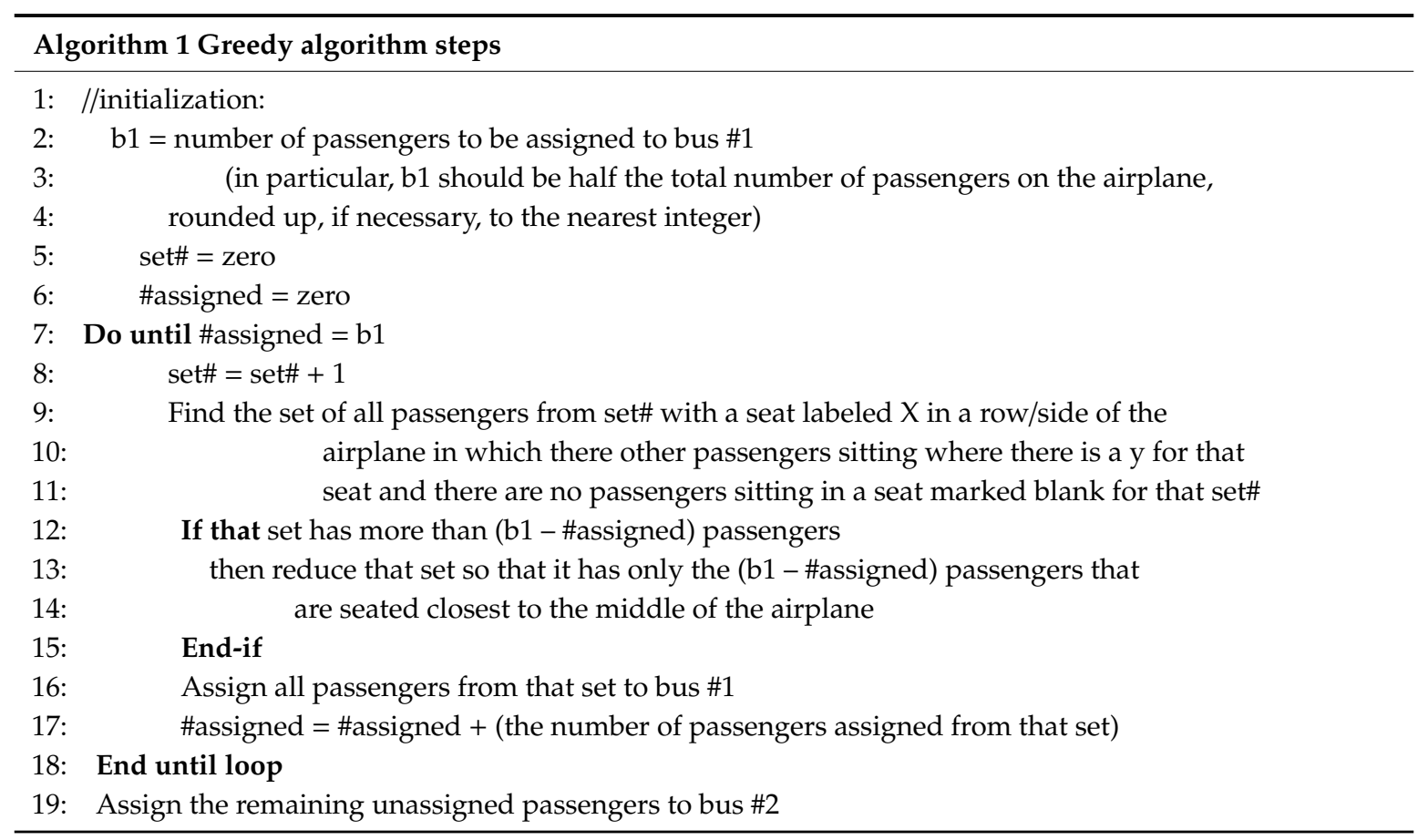




\section{Numerical Results}

Using the BehaviorSpace tool [15] offered by NetLogo, 10,000 simulations have been conducted for each of the considered cases. We consider various aspects such as the most efficient number of passengers to get on each apron bus, the average boarding time under different luggage situations, and by considering random passenger seat assignments and preferential passenger seat assignments, and other aspects related to passengers boarding, such as the number of seat and aisle interferences.

\subsection{Varying the Number of Passengers to be Boarded into the First Apron Bus}

In this section, we investigate the best number of passengers to board each apron bus when the greedy method is used. In this investigation, we consider both types of seat assignments-random seat assignments and preferential seat assignments. For both seat assignments, we vary the number of passengers boarding the first apron bus between 64 and 80, for an airplane having an 80\% occupancy, namely 144 passengers, and for the S7 luggage situation. The simulation results are presented in Table 3 for the random seat assignments situation. From this data we observe that the lowest boarding time results from assigning 72 of the airplane's passengers (half of the 144 total) to the first apron bus. In the tables with boarding times (measured in the time unit of ticks) the lowest (best) boarding times are in bold font. The confirms our hypothesis prior to conducting the experiment that assigning an equal number of passengers to each apron bus is best.

Table 3. The average boarding time (in ticks) for $80 \%$ occupancy level, random seat assignments, and the S7 luggage situation.

\begin{tabular}{cccccccccc}
\hline $\begin{array}{c}\text { No. of Passengers } \\
\text { Assigned to First Bus }\end{array}$ & $\mathbf{6 4}$ & $\mathbf{6 6}$ & $\mathbf{6 8}$ & $\mathbf{7 0}$ & $\mathbf{7 2}$ & $\mathbf{7 4}$ & $\mathbf{7 6}$ & $\mathbf{7 8}$ & $\mathbf{8 0}$ \\
\hline No. of ticks & 125.9 & 125.2 & 124.5 & 123.6 & $\mathbf{1 2 1 . 1}$ & 122.3 & 122.6 & 124.1 & 124.8 \\
\hline
\end{tabular}

We conducted similar simulations for preferential seating assignments. As illustrated in Table 4, again the minimum boarding time results from assigning half of the airplane's passengers to the first apron bus. Assigning 74 passengers to the first bus is better than assigning 70 passengers for both the random and preferential seating assignments. That is why our proposed greedy method suggests rounding up (rather than rounding down) the number of passengers boarding the first bus in the event of an odd number of passengers occupying seats in the airplane.

Table 4. The average boarding time (in ticks) for $80 \%$ occupancy level, preferential seat assignments, and S7 luggage situation.

\begin{tabular}{cccccccccc}
\hline $\begin{array}{c}\text { No. of Passengers } \\
\text { Assigned to First Bus }\end{array}$ & $\mathbf{6 4}$ & $\mathbf{6 6}$ & $\mathbf{6 8}$ & $\mathbf{7 0}$ & $\mathbf{7 2}$ & $\mathbf{7 4}$ & $\mathbf{7 6}$ & $\mathbf{7 8}$ & $\mathbf{8 0}$ \\
\hline No. of ticks & 131.5 & 130.9 & 129.7 & 128.2 & $\mathbf{1 2 5 . 4}$ & 127.1 & 128.2 & 129.3 & 130.1 \\
\hline
\end{tabular}

\subsection{Random Passenger Seating Assignment}

Four occupancy levels, the luggage situation in accordance with S4, and random seat assignments are considered in Table 5 with the average boarding times resulting from various boarding methods reported in this table. Comparing the results from three best-performing methods from the literature-Reverse pyramid-A, Hybrid-A, and Hybrid-B-we observe that in all the cases, when using the greedy method (highlighted in grey in Table 5), the average boarding time is smaller than obtained through the literature's three best methods applicable to boading a partially occupied two-door airplane when using two apron buses. On average, there is a 3.86\% decrease in boarding time when using the greedy method instead of the literature's method that performs best for that occupany level and luggage situation. Furthermore, when compared to the random boarding method, the overall average 
improvement is $32.36 \%$. This corresponds to an average time reduction of 83.5 ticks (69.58 seconds) between the greedy method and the random method used in practice. By considering an average cost of $\$ 53.5$ per minute [9,10], a cost reduction of $\$ 62$ is made on each flight with similar characteristics to the one considered in the study, when the greedy method is used instead of random method.

Table 5. The average boarding times (in ticks) for partial occupancy levels, random seat assignments, and the S4 luggage situation.

\begin{tabular}{|c|c|c|c|c|c|c|}
\hline \multirow{3}{*}{ Boarding method } & \multicolumn{4}{|c|}{ Luggage Situation: S4 } & \multirow{3}{*}{ Average boarding time } & \multirow{6}{*}{$\begin{array}{l}\text { Boarding time improvement } \\
\text { when compared to the best } \\
\text { performing method/with the } \\
\text { method used in practice }\end{array}$} \\
\hline & \multicolumn{4}{|c|}{ Occupancy Level: } & & \\
\hline & $60 \%$ & $70 \%$ & $80 \%$ & $90 \%$ & & \\
\hline $\begin{array}{l}\text { Benchmark-M1: Reverse } \\
\text { Pyramid-A }\end{array}$ & 149 & 172 & 192 & 214 & 181.75 & \\
\hline $\begin{array}{l}\text { Benchmark-M3: } \\
\text { Hybrid-B }\end{array}$ & 149 & 171 & 207 & 217 & 186.00 & \\
\hline Greedy & 140 & 162 & 188 & 208 & 174.50 & \\
\hline
\end{tabular}

By varying across all the luggage situations, with random seat assignments, for a particular occupancy level of $80 \%$, the data in Table 6 is obtained. Based on the individual luggage situations, we observe that in the $\mathrm{S} 7$ case, the time improvement is $8.33 \%$ when the greedy method (highlighted in grey in Table 6) is used instead of the literature's best-performing methods for this situation of Reverse Pyramid-A and Hybrid-A. Furthermore, for S7, when comparing the results of the greedy method with the random boarding method used in practice by airline companies, a time reduction of 94 ticks is recorded, equivalent to a $43.72 \%$ improvement. Smaller time improvements are attained as the number of hand luggage increase, for example in the $\mathrm{S} 1$ situation, the time improvement from using the greedy method is just 6 ticks faster than when using Hybrid-A. Considering all the luggage situations, an average of $3.91 \%$ results from using the greedy method instead of the literature's best performing methods for each situation.

Table 6. The average boarding times (in ticks) for $80 \%$ occupancy level, random seat assignments, and S1-S7 luggage situations.

\begin{tabular}{|c|c|c|c|c|c|c|c|c|c|}
\hline \multirow{3}{*}{ Boarding method } & \multicolumn{7}{|c|}{ Occupancy Level: $80 \%$} & \multirow{3}{*}{ Average boarding time } & \multirow{7}{*}{$\begin{array}{l}\text { Boarding time improvement } \\
\text { when compared to the best } \\
\text { performing method/with the } \\
\text { method used in practice }\end{array}$} \\
\hline & \multicolumn{7}{|c|}{ Luggage Situations: } & & \\
\hline & S1 & S2 & S3 & $\mathrm{S} 4$ & S5 & S6 & S7 & & \\
\hline $\begin{array}{l}\text { Benchmark-practice: } \\
\text { Random }\end{array}$ & 339 & 315 & 297 & 273 & 262 & 239 & 215 & 277.14 & \\
\hline $\begin{array}{l}\text { Benchmark-M1: } \\
\text { Reverse Pyramid-A }\end{array}$ & 251 & 229 & 212 & 192 & 177 & 161 & 132 & 193.43 & \\
\hline $\begin{array}{l}\text { Benchmark-M2: } \\
\text { Hybrid-A }\end{array}$ & 249 & 233 & 210 & 193 & 179 & 159 & 132 & 193.57 & \\
\hline $\begin{array}{l}\text { Benchmark-M3: } \\
\text { Hybrid-B }\end{array}$ & 251 & 232 & 213 & 207 & 178 & 159 & 133 & 196.14 & \\
\hline Greedy & 243 & 224 & 204 & 188 & 169 & 152 & 121 & 185.86 & $3.91 \% / 32.94 \%$ \\
\hline
\end{tabular}

Considering all the luggage situations and an $80 \%$ occupancy level, we observe that the average time improvement, when compared to the random boarding method commonly used in practice, is from 277.14 ticks to 185.86 ticks, representing an average time reduction of $32.94 \%$. 


\subsection{Preferential Passenger Seat Assignments}

For the preferential seat assignments case, the data in Table 7 is determined for the case of S4 luggage situation and various occupancy levels. As with random seat assignments, we observe that in all the cases the average boarding time obtained through the use of the greedy method (highlighted in grey in Table 7) is below the times recorded by the benchmark methods. The overall average time improvement is $2.21 \%$ when compared with the literatue's best-performing method of each situation and $32.99 \%$ when compared to the random boarding method commonly used in practice. Furthermore, this corresponds to an average boarding time reduction of 87.25 ticks ( 72.71 seconds) between the cases in which the greedy method is used instead of random boarding, equivalent to a cost reduction of $\$ 64.83$ per flight.

Table 7. The average boarding times (in ticks) for partial occupancy levels, preferential seat assignments, and the S4 luggage situation.

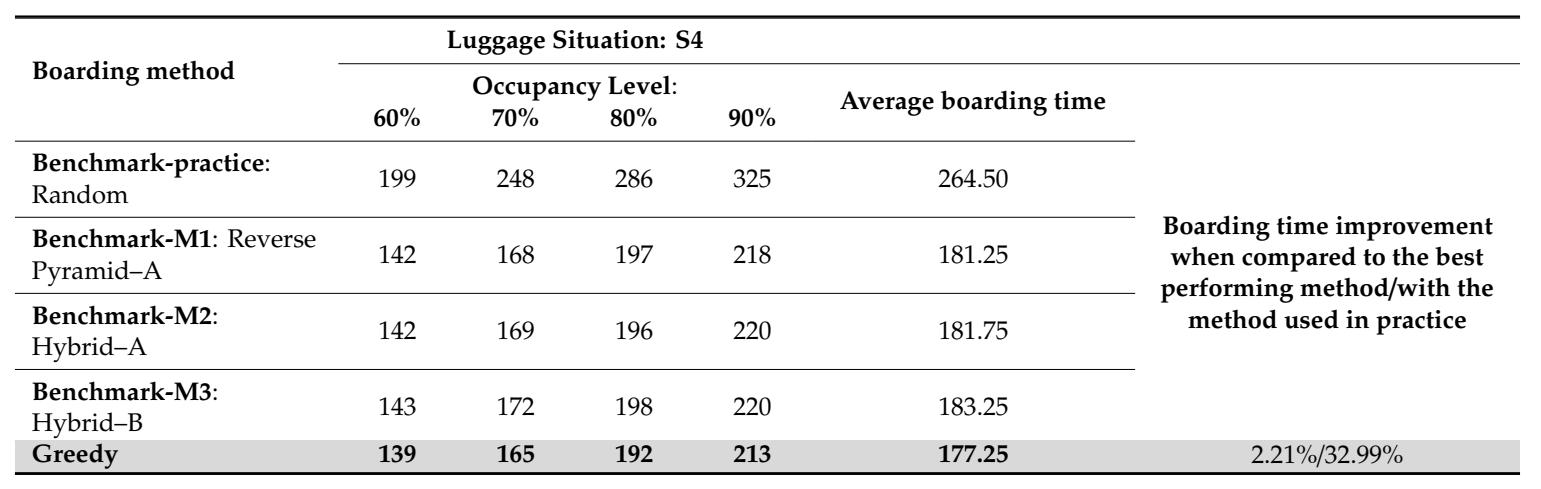

Varying across all the luggage situations and for an $80 \%$ occupancy level and preferential seating assignments, the data in Table 8 is obtained. The highest time reduction in this case is for the S7 luggage situation, where the greedy method (highlighted in grey in Table 8 ) provides a boarding time reduced by $6.72 \%$ when compared to the literature's benchmark method that performs best for each situation.

Table 8. The average boarding times (in ticks) for $80 \%$ occupancy level, preferential seat assignments, and S1-S7 luggage situations.

\begin{tabular}{|c|c|c|c|c|c|c|c|c|c|}
\hline \multirow{3}{*}{ Boarding method } & \multicolumn{7}{|c|}{ Occupancy Level: $80 \%$} & \multirow{3}{*}{ Average boarding time } & \\
\hline & \multicolumn{7}{|c|}{ Luggage Situations: } & & \multirow{6}{*}{$\begin{array}{l}\text { Boarding time improvement } \\
\text { when compared to the best } \\
\text { performing method/with the } \\
\text { method used in practice }\end{array}$} \\
\hline & S1 & $\mathrm{S} 2$ & S3 & $\mathrm{S} 4$ & S5 & S6 & S7 & & \\
\hline $\begin{array}{l}\text { Benchmark-practice: } \\
\text { Random }\end{array}$ & 362 & 332 & 306 & 286 & 268 & 243 & 220 & 288.14 & \\
\hline $\begin{array}{l}\text { Benchmark-M1: } \\
\text { Reverse Pyramid-A }\end{array}$ & 257 & 237 & 215 & 197 & 177 & 161 & 134 & 196.86 & \\
\hline $\begin{array}{l}\text { Benchmark-M2: } \\
\text { Hybrid-A }\end{array}$ & 255 & 239 & 215 & 196 & 179 & 160 & 134 & 196.86 & \\
\hline $\begin{array}{l}\text { Benchmark-M3: } \\
\text { Hybrid-B }\end{array}$ & 254 & 237 & 215 & 198 & 183 & 160 & 134 & 197.29 & \\
\hline Greedy & 253 & 232 & 213 & 192 & 174 & 157 & 125 & 192.29 & $2.32 \% / 33.27 \%$ \\
\hline
\end{tabular}

Considering the boarding time for the random boarding method in the case of preferential seat assignment for the S7 luggage situation, $80 \%$ occupancy level (220 ticks) and the time provided by the greedy method (125 ticks), a time improvement of $43.18 \%$ results.

Furthermore, by considering the average time for the random boarding method in all the luggage cases, for $80 \%$ occupancy level (288.14 ticks) and the average boarding time provided by the greedy method (192.29 ticks), the improvement in boarding time is $33.27 \%$. 


\subsection{Comparing the Methods in Terms of Seat Interferences}

We analyzed the seat interferences to provide further insight into the performance provided by the greedy method. The S7 luggage situation, $80 \%$ occupancy level, and the literature's benchmark methods and the greedy method are considered. The $\mathrm{S7}$ luggage situation has been preferred as in this case, there is no aisle interference and the overall boarding time is mostly explained by the presence of the seat interferences. The NetLogo 6.1.0 model and a few video simulations featuring $80 \%$ occupancy level, S7 lugagge situation, random passenger seating assignment for the proposed greedy method and for the considered benchmark methods can be accessed as described in the Supplementary Materials of this paper.

The data in Table 9 has been obtained for the random seat assignments and the data in Table 10 for the preferential seat assignments. In both tables, only the cases in which the seat interferences had affected passengers have been considered, meaning that at least one person was waiting in the aisle as a passenger engaged in one of the types of interferences was occupying the aisle.

Table 9. The average number of interferences with affected passengers for partial occupancy levels, random seat assignments, and the S7 luggage situation, 80\% occupancy level.

\begin{tabular}{lcccc}
\hline \multirow{2}{*}{ Boarding Method } & \multicolumn{4}{c}{ Luggage Situation: S7, Occupancy Level 80\% } \\
\cline { 2 - 5 } & Type 1 & Seat Interferences \\
Type 2 & Type 3 & Type 4 \\
\hline $\begin{array}{l}\text { Benchmark-practice: } \\
\text { Random }\end{array}$ & 7.8 & 6.9 & 6.7 & 13.6 \\
\hline $\begin{array}{l}\text { Benchmark-M1: } \\
\begin{array}{l}\text { Reverse } \\
\text { Pyramid-A }\end{array}\end{array}$ & 0 & 7.3 & 0 & 8.1 \\
\hline $\begin{array}{l}\text { Benchmark-M2: } \\
\text { Hybrid-A }\end{array}$ & 0 & 7.4 & 0 & 8.0 \\
\hline $\begin{array}{l}\text { Benchmark-M3: } \\
\text { Hybrid-B }\end{array}$ & 0 & 7.4 & 0 & 8.1 \\
\begin{tabular}{l} 
Greedy \\
\hline
\end{tabular} & 0.7 & 3.0 & 0.8 & 9.7 \\
\hline
\end{tabular}

The presence of the interferences is usually connected with less-satisfied passengers, thus, one might also be interested in reducing the number of the interferences. Considering all the types of seat interferences, we see that, on average, the greedy method (highlighted in grey) results in a total of 14.2 interferences with affected passengers, Reverse Pyramid-A and Hybrid-A have 15.4 seat interferences with affected passengers, Hybrid-B has 15.5, and the random boarding method has 35 seat interferences for the case of random seat assignments (Table 9).

For the preferential seat assignment, the greedy method results in an average of 14.4 seat interferences with affected passengers, while the three benchmarks from the literature have an average of 15.3 seat interferences with affected passengers. The random boarding method has an average of 34.8 seat interferences with affected passengers (Table 10).

Considering the data in Tables 9 and 10, we see that the greedy method provides advantages for the passengers' comfort as the method boards them with a minimal number of seat interferences. We further note that the data on seat interferences provides insight into why the greedy method consistently results in the best boarding time. Much of the greedy method's benefits results from having fewer seat interferences of type 2. Each type 2 interference takes longer than the type 3 and type 4 interferences that occur more frequently with the greedy method than with the other best performing methods. While the three best performing benchmark methods have none of the (time consuming) type 1 interferences, the greedy method occasionally has these interferences; with the greedy method though, the type 1 interferences are limited to passengers boarding the first apron bus and sitting very 
close to the middle of the airplane-a condition where the type 1 seat interference is least impactful on boarding time.

Table 10. The average number of interferences with affected passengers for partial occupancy levels, preferential seat assignments, and the S7 luggage situation, $80 \%$ occupancy level.

\begin{tabular}{ccccc}
\hline \multirow{2}{*}{ Boarding Method } & \multicolumn{4}{c}{ Luggage Situation: S7, Occupancy Level 80\% } \\
\cline { 2 - 5 } & Type 1 & Seat Interferences & \\
Type 2 & Type 3 & Type 4 \\
\hline $\begin{array}{c}\text { Benchmark-practice: } \\
\text { Random }\end{array}$ & 7.5 & 5.7 & 10.7 & 10.9 \\
\hline $\begin{array}{c}\text { Benchmark-M1: } \\
\text { Reverse } \\
\text { Pyramid-A }\end{array}$ & 0 & 7.6 & 0 & 7.7 \\
\hline $\begin{array}{c}\text { Benchmark-M2: } \\
\text { Hybrid-A }\end{array}$ & 0 & 7.7 & 0 & 7.6 \\
\hline $\begin{array}{c}\text { Benchmark-M3: } \\
\text { Hybrid-B }\end{array}$ & 0 & 7.7 & 0 & 7.6 \\
\hline Greedy & 0.6 & 3.2 & 1.4 & 9.2 \\
\hline
\end{tabular}

\section{Conclusions}

This paper extends the research on airplane boarding in the presence of two apron buses when the front and rear doors of the airplane are used. In particular, this paper proposes a greedy method that we implemented using an agent-based approach in NetLogo. The greedy method is tested under various partial airplane occupancy considering seven luggage situations and two seat assignment situations: with and without preferred seat assignments. When compared to the best-known practices in the literature, the proposed greedy method provides a boarding time improvement up to $8.33 \%$. Furthermore, when compared to the random boarding method (commonly used in practice), the time improvement is up to $43.72 \%$.

Furthermore, the proposed greedy approach provides a relatively comfortable environment for the passengers while boarding because it results in the lowest average number of seat interferences with affected passengers. Finally, we found that the best greedy results are attained when an equal number of passengers boards each of the two apron buses.

Future research can extend the concepts of this paper to address alternative airplane configurations (e.g., wide-body, two-aisle airplanes) and the consideration of groups of passengers (e.g., families) traveling together.

Supplementary Materials: The NetLogo 6.1.0 model and a few video simulations featuring $80 \%$ occupancy level, S7 lugagge situation, random passenger seating assignment for the proposed greedy method and for the considered benchmark methods can be accessed at: https://github.com/liviucotfas/ase-2019-airplane-boardingusing-apron-buses-greedy-algorithm.

Author Contributions: Conceptualization: R.J.M., L.-A.C., and C.D.; data curation: L.-A.C.; formal analysis: R.J.M., C.D., and M.S.; investigation: L.-A.C., C.D., and M.S.; methodology: R.J.M., L.-A.C., and C.D.; resources: L.C. and A.G.M.; software: L.-A.C., and C.D.; supervision: R.J.M.; validation: R.J.M.; visualization: L.-A.C., and C.D.; writing—original draft: C.D.; writing—review and editing: R.J.M., L.-A.C., M.S., L.C., and A.G.M..

Funding: The authors acknowledge no funding.

Conflicts of Interest: The authors declare no conflict of interest. 


\section{Appendix A NetLogo model GUI}

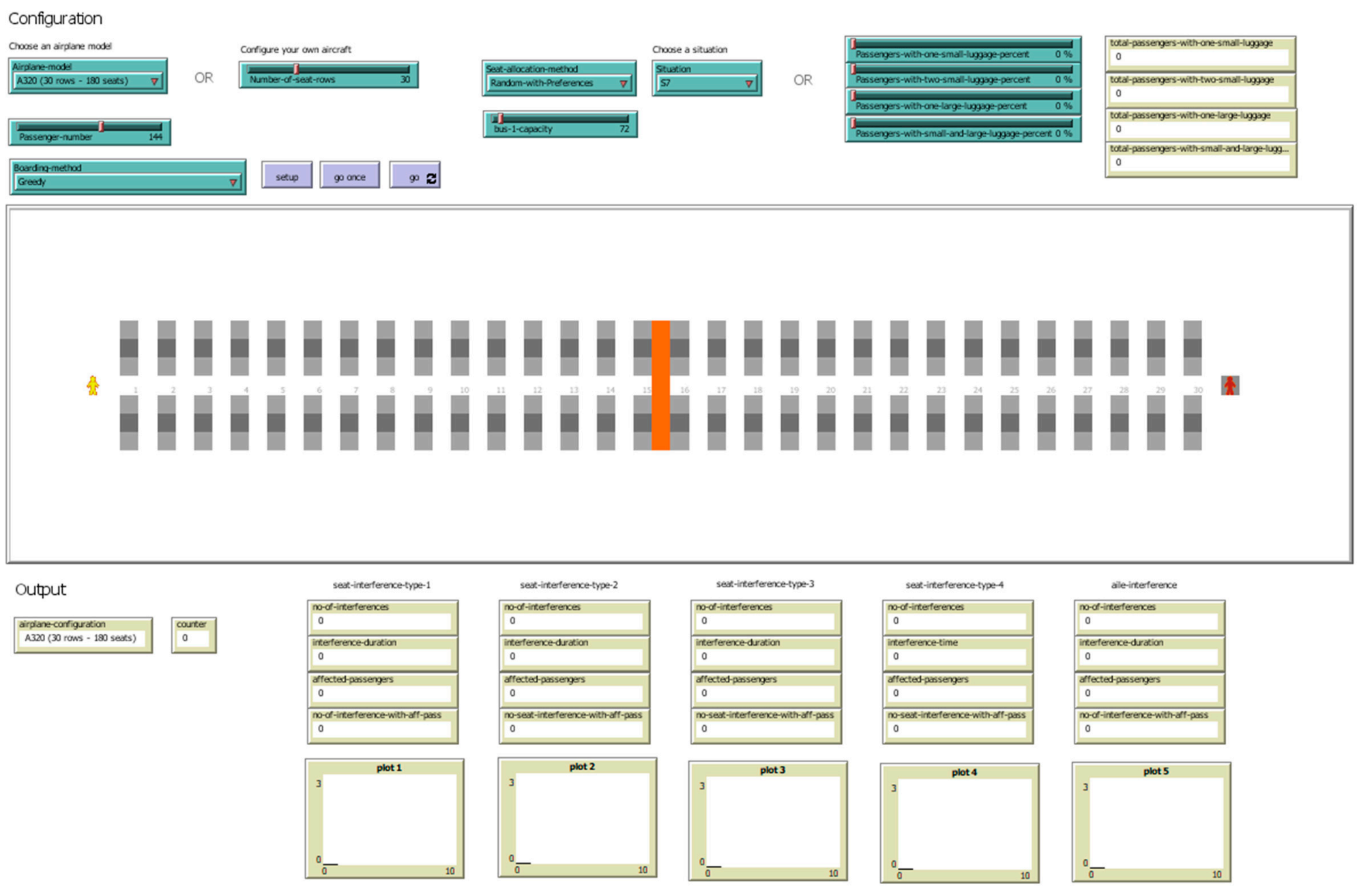

Figure A1. Agent-based model GUI. 


\section{References}

1. Doganis, P.R.; Doganis, R. The Airport Business; Routledge: Abingdon, UK, 2005; ISBN 978-1-134-89281-5.

2. Milne, R.J.; Delcea, C.; Cotfas, L.-A.; Salari, M. New methods for two-door airplane boarding using apron buses. J. Air Transp. Manag. 2019, 80, 101705. [CrossRef]

3. Milne, R.J.; Kelly, A.R. A new method for boarding passengers onto an airplane. J. Air Transp. Manag. 2014, 34, 93-100. [CrossRef]

4. Steffen, J.H. Optimal boarding method for airline passengers. J. Air Transp. Manag. 2008, 14, 146-150. [CrossRef]

5. Soolaki, M.; Mahdavi, I.; Mahdavi-Amiri, N.; Hassanzadeh, R.; Aghajani, A. A new linear programming approach and genetic algorithm for solving airline boarding problem. Appl. Math. Model. 2012, 36, 4060-4072. [CrossRef]

6. Milne, R.J.; Salari, M.; Kattan, L. Robust Optimization of Airplane Passenger Seating Assignments. Aerospace 2018, 5, 80. [CrossRef]

7. Tang, T.-Q.; Yang, S.-P.; Ou, H.; Chen, L.; Huang, H.-J. An aircraft boarding model with the group behavior and the quantity of luggage. Transp. Res. Part C Emerg. Technol. 2018, 93, 115-127. [CrossRef]

8. $\quad$ van den Briel, M.H.L.; Villalobos, J.R.; Hogg, G.L.; Lindemann, T.; Mulé, A.V. America West Airlines Develops Efficient Boarding Strategies. Interfaces 2005, 35, 191-201. [CrossRef]

9. Nyquist, D.C.; McFadden, K.L. A study of the airline boarding problem. J. Air Transp. Manag. 2008, 14, 197-204. [CrossRef]

10. Steiner, A.; Philipp, M. Speeding up the airplane boarding process by using pre-boarding areas. In Proceedings of the Swiss Transport Research Conference, Ascona, Switzerland, 9-11 September 2009.

11. Milne, R.J.; Salari, M. Optimization of assigning passengers to seats on airplanes based on their carry-on luggage. J. Air Transp. Manag. 2016, 54, 104-110. [CrossRef]

12. Delcea, C.; Cotfas, L.-A.; Salari, M.; Milne, R.J. Investigating the Random Seat Boarding Method without Seat Assignments with Common Boarding Practices Using an Agent-Based Modeling. Sustainability 2018, 10, 4623. [CrossRef]

13. Eurocontrol All-Causes Delay and Cancellations to Air Transport in Europe. 2017. Available online: https://www.eurocontrol.int/sites/default/files/publication/files/coda-digest-annual-2017.pdf (accessed on 10 February 2019).

14. Eurocontrol Eurocontrol Seven-Years Forecast. Available online: https://www.eurocontrol.int/sites/default/ files/content/documents/official-documents/forecasts/seven-year-flights-service-units-forecast-2018-2024Feb2018.pdf (accessed on 10 September 2018).

15. Wilensky, U.; Rand, W. An Introduction to Agent-Based Modeling: Modeling Natural, Social, and Engineered Complex Systems with NetLogo; The MIT Press: Cambridge, MA, USA, 2015; ISBN 978-0-262-73189-8.

16. Cotfas, L.-A.; Delcea, C.; Milne, R.J.; Salari, M.; Craciun, L.; Molanescu, A.G. Testing New Methods for Boarding a Partially Occupied Airplane using Apron Buses. Symmetry 2019, 11, 1044. [CrossRef]

17. Bidanda, R.; Winakor, J.; Geng, Z.; Vidic, N. A Review of Optimization Models for Boarding a Commercial Airplane. In Proceedings of the 24th International Conference on Production Research, Poznan, Poland, 30 July-3 August 2017; pp. 1-6.

18. SeatGuru. Guide to Airline Boarding Procedures. Available online: https://www.seatguru.com/traveltips/ boarding_procedures.php (accessed on 21 February 2019).

19. Steffen, J.H. A statistical mechanics model for free-for-all airplane passenger boarding. Am. J. Phys. 2008, 76, 1114-1119. [CrossRef]

20. Steffen, J.H.; Hotchkiss, J. Experimental test of airplane boarding methods. J. Air Transp. Manag. 2012, 18, 64-67. [CrossRef]

21. Jafer, S.; Mi, W. Comparative Study of Aircraft Boarding Strategies Using Cellular Discrete Event Simulation. Aerospace 2017, 4, 57. [CrossRef]

22. Bachmat, E.; Berend, D.; Sapir, L.; Skiena, S.; Stolyarov, N. Analysis of Airplane Boarding Times. Oper. Res. 2009, 57, 499-513. [CrossRef]

23. Kierzkowski, A.; Kisiel, T. The Human Factor in the Passenger Boarding Process at the Airport. Procedia Eng. 2017, 187, 348-355. [CrossRef] 
24. Van Landeghem, H.; Beuselinck, A. Reducing passenger boarding time in airplanes: A simulation based approach. Eur. J. Oper. Res. 2002, 142, 294-308. [CrossRef]

25. Delcea, C.; Cotfas, L.-A.; Paun, R. Agent-Based Evaluation of the Airplane Boarding Strategies' Efficiency and Sustainability. Sustainability 2018, 10, 1879. [CrossRef]

26. Qiang, S.-J.; Jia, B.; Xie, D.-F.; Gao, Z.-Y. Reducing airplane boarding time by accounting for passengers' individual properties: A simulation based on cellular automaton. J. Air Transp. Manag. 2014, 40, 42-47. [CrossRef]

27. Ferrari, P.; Nagel, K. Robustness of Efficient Passenger Boarding Strategies for Airplanes. Transp. Res. Rec. J. Transp. Res. Board 2005, 1915, 44-54. [CrossRef]

28. Hutter, L.; Jaehn, F.; Neumann, S. Influencing Factors on Airplane Boarding Times. Omega 2018, 87, 177-190. [CrossRef]

29. Notomista, G.; Selvaggio, M.; Sbrizzi, F.; Di Maio, G.; Grazioso, S.; Botsch, M. A fast airplane boarding strategy using online seat assignment based on passenger classification. J. Air Transp. Manag. 2016, 53, 140-149. [CrossRef]

30. Delcea, C.; Cotfas, L.-A.; Craciun, L.; Molanescu, A.G. Are Seat and Aisle Interferences Affecting the Overall Airplane Boarding Time? An Agent-Based Approach. Sustainability 2018, 10, 4217. [CrossRef]

31. Ren, X.; Xu, X. Experimental analyses of airplane boarding based on interference classification. J. Air Transp. Manag. 2018, 71, 55-63. [CrossRef]

32. Qiang, S.; Jia, B.; Huang, Q. Evaluation of Airplane Boarding/Deboarding Strategies: A Surrogate Experimental Test. Symmetry 2017, 9, 222. [CrossRef]

33. Schultz, M. Implementation and application of a stochastic aircraft boarding model. Transp. Res. Part $C$ Emerg. Technol. 2018, 90, 334-349. [CrossRef]

34. Schultz, M.; Kunze, T.; Fricke, H. Boarding on the critical path of the turnaround. In Proceedings of the 10th USA/Europe Air Traffic Management Research and Development Seminar, Chicago, IL, USA, 10-13 June 2013; pp. 1-10.

35. Schultz, M.; Schulz, C.; Fricke, H. Efficiency of Aircraft Boarding Procedures. In Proceedings of the 3rd International Conference on Research in Airport Transportation, Fairfax, VA, USA, 1-4 June 2008; pp. 371-391.

36. Jaehn, F.; Neumann, S. Airplane boarding. Eur. J. Oper. Res. 2015, 244, 339-359. [CrossRef]

37. Marelli, S.; Mattocks, G.; Merry, R. The role of computer simulation in reducing airplane turnaround time. Boeing Aero Mag. 1998, 1, 1-5.

38. Delcea, C.; Cotfas, L.-A.; Chiriță, N.; Nica, I. A Two-Door Airplane Boarding Approach When Using Apron Buses. Sustainability 2018, 10, 3619. [CrossRef]

39. Gao, M.; Zhou, L.; Chen, Y. An Alternative Approach for High Speed Railway Carrying Capacity Calculation Based on Multiagent Simulation. Discret. Dyn. Nat. Soc. 2016, 2016, e4278073. [CrossRef]

40. Vo, T.T.A.; van der Waerden, P.; Wets, G. Micro-simulation of Car Drivers' Movements at Parking Lots. Procedia Eng. 2016, 142, 100-107. [CrossRef]

41. Shqair, M.; Altarazi, S.; Al-Shihabi, S. A statistical study employing agent-based modeling to estimate the effects of different warehouse parameters on the distance traveled in warehouses. Simul. Model. Pract. Theory 2014, 49, 122-135. [CrossRef]

42. Faroqi, H.; Mesgari, M.-S. Agent-Based Crowd Simulation Considering Emotion Contagion For Emergency Evacuation Problem. ISPRS Int. Arch. Photogramm. Remote Sens. Spat. Inf. Sci. 2015, 40, 193-196. [CrossRef]

43. Liu, R.; Jiang, D.; Shi, L. Agent-based simulation of alternative classroom evacuation scenarios. Front. Archit. Res. 2016, 5, 111-125. [CrossRef]

44. Gutierrez-Milla, A.; Borges, F.; Suppi, R.; Luque, E. Individual-oriented Model Crowd Evacuations Distributed Simulation. Procedia Comput. Sci. 2014, 29, 1600-1609. [CrossRef]

45. Wang, H.; Mostafizi, A.; Cramer, L.A.; Cox, D.; Park, H. An agent-based model of a multimodal near-field tsunami evacuation: Decision-making and life safety. Transp. Res. Part C Emerg. Technol. 2016, 64, 86-100. [CrossRef]

46. Delcea, C.; Cotfas, L.-A. Increasing awareness in classroom evacuation situations using agent-based modeling. Phys. A Stat. Mech. Appl. 2019, 523, 1400-1418. [CrossRef]

47. Delcea, C.; Cotfas, L.-A.; Trică, C.; Crăciun, L.; Molanescu, A. Modeling the Consumers Opinion Influence in Online Social Media in the Case of Eco-friendly Products. Sustainability 2019, 11, 1796. [CrossRef] 
48. Wooldridge, M.; Jennings, N.R. Intelligent agents: Theory and practice. Knowl. Eng. Rev. 1995, 10, 115-152. [CrossRef]

49. Getchell, A. Agent-Based Modeling. 2015. Available online: http://rgdoi.net/10.13140/RG.2.1.2880.8803 (accessed on 17 February 2019).

50. Delcea, C.; Bradea, I.A. Economic Cybernetics. An Equation-Based Modeling and Agent-Based Modeling Approach; Editura Universitara: Bucharest, Romania, 2017; ISBN 978-606-28-0629-3.

51. Schultz, M. Fast Aircraft Turnaround Enabled by Reliable Passenger Boarding. Aerospace 2018, 5, 8. [CrossRef]

52. Schultz, M. Field Trial Measurements to Validate a Stochastic Aircraft Boarding Model. Aerospace 2018, 5, 27. [CrossRef]

53. Bazargan, M. A linear programming approach for aircraft boarding strategy. Eur. J. Oper. Res. 2007, 183, 394-411. [CrossRef]

54. Schultz, M. A metric for the real-time evaluation of the aircraft boarding progress. Transp. Res. Part C Emerg. Technol. 2018, 86, 467-487. [CrossRef]

55. Audenaert, J.; Verbeeck, K.; Berghe, G. Multi-agent based simulation for boarding. In Proceedings of the 21st Benelux Conference on Artificial Intelligence, Eindhoven, The Netherlands, 29-30 October 2009; pp. 3-10.

56. Binev, P.; Cohen, A.; Dahmen, W.; DeVore, R.; Petrova, G.; Wojtaszczyk, P. Convergence Rates for Greedy Algorithms in Reduced Basis Methods. SIAM J. Math. Anal. 2011, 43, 1457-1472. [CrossRef]

(C) 2019 by the authors. Licensee MDPI, Basel, Switzerland. This article is an open access article distributed under the terms and conditions of the Creative Commons Attribution (CC BY) license (http://creativecommons.org/licenses/by/4.0/). 